Chronic Obstructive Pulmonary Diseases: Journal of the COPD Foundation

\author{
Original Research
}

\title{
Immunoglobulin E as a Biomarker for the Overlap of Atopic Asthma and Chronic Obstructive Pulmonary Disease
}

\author{
Craig P. Hersh, MD, MPH ${ }^{1}$ Soumya Zacharia, BTech ${ }^{1}$ Ram Prakash Arivu Chelvan, BE ${ }^{1}$ \\ Lystra P. Hayden, MD, MS ${ }^{1}$ Ali Mirtar, $\mathrm{PhD}^{2}$ Sara Zarei, PhD, MD ${ }^{1,2}$ Nirupama Putcha, MD, MHS \\ and the COPDGene ${ }^{\circledR}$ Investigators
}

\begin{abstract}
Asthma-COPD overlap (ACO) is a common clinical syndrome, yet there is no single objective definition. We hypothesized that immunoglobulin E (IgE) measurements could be used to refine the definition of ACO. In baseline plasma samples from 2870 participants in the COPD Genetic Epidemiology (COPDGene ${ }^{\circledR}$ ) study, we measured total IgE levels and specific IgE levels to 6 common allergens. Compared to usual chronic obstructive pulmonary disease (COPD), participants with ACO (based on self-report of asthma) had higher total IgE levels (median 67.0 versus $42.2 \mathrm{IU} / \mathrm{ml}$ ) and more frequently had at least one positive specific IgE (43.5\% versus $24.5 \%$ ). We previously used a strict definition of ACO in participants with COPD, based on self-report of a doctor's diagnosis of asthma before age 40. This strict ACO definition was refined by the presence of atopy, determined by total IgE > $100 \mathrm{IU} / \mathrm{ml}$ or at least one positive specific IgE, as was the broader definition of ACO based on self-reported asthma history. Participants with all 3 ACO definitions were younger (mean age 60.0-61.3 years), were more commonly African American (36.8\%-44.2\%), had a higher exacerbation frequency (1.0-1.2 in the past year), and had more airway wall thickening on quantitative analysis of chest computed tomography (CT) scans. Among participants with ACO, 37\%-46\% did not have atopy; these individuals had more emphysema on chest CT scan. Based on associations with exacerbations and CT airway disease, IgE did not clearly improve the clinical definition of ACO. However, IgE measurements could be used to subdivide individuals with atopic and non-atopic ACO, who might have different biologic mechanisms and potential treatments.
\end{abstract}

Abbreviations: asthma-COPD overlap, ACO; immunoglobulin E, IgE; COPD Genetic Epidemiology, COPDGene ${ }^{\circledR}$; chronic obstructive pulmonary disease, COPD; computed tomography, CT; Global Initiative for Asthma, GINA; Global initiative for chronic Obstructive Lung Disease, GOLD; forced expiratory volume in $1 \mathrm{sec}, \mathbf{F E V}_{\mathbf{1}}$; forced vital capacity, FVC; Hounsfield unit, HU; interleukin, IL

Funding Support: This study was supported by National Institutes of Health grants R01HL130512, R01HL125583, K23HL123594, P01HL132825, U01HL089856, and U01HL089897 and a grant from Novartis. The COPDGene ${ }^{\circledR}$ study (NCT00608764) is also supported by the COPD Foundation through contributions made to an Industry Advisory Committee comprised of AstraZeneca, BoehringerIngelheim, GlaxoSmithKline, Novartis, and Sunovion.

Date of Acceptance: October 10, 2019

Citation: Hersh CP, Zacharia S, Prakash R, et al and the COPDGene Investigators. Immunoglobulin E as a biomarker for the overlap of atopic asthma and chronic obstructive pulmonary disease. Chronic Obstr Pulm Dis. 2020;7(1):1-12. doi: https://doi.org/10.15326/ jcopdf.7.1.2019.0138

1 Channing Division of Network Medicine, Brigham and Women's Hospital, Boston, Massachusetts

2 Arasila Biotech, San Diego, California

3 Division of Pulmonary and Critical Care Medicine, Johns Hopkins University, Baltimore, Maryland

\section{Address correspondence to:}

Craig P. Hersh, MD, MPH

Channing Division of Network Medicine

Brigham and Women's Hospital

181 Longwood Ave

Boston, MA 02115

Phone: 617-525-0729

Email: craig.hersh@channing.harvard.edu 


\section{Keywords:}

asthma, atopy, chest CT scan, chronic obstructive pulmonary disease, immunoglobulin $\mathrm{E}$

\section{Note: This article has an online supplement.}

\section{Introduction}

Many patients with chronic obstructive pulmonary disease (COPD) also carry a diagnosis of asthma, termed asthma-COPD overlap (ACO). ${ }^{1}$ ACO has been associated with increased symptoms, increased exacerbations, and greater health care utilization. Given the high prevalence and clinical relevance, multiple groups have proposed consensus definitions. ${ }^{2-4}$ The Global Initiative for Asthma (GINA) and the Global initiative for chronic Obstructive Lung Disease (GOLD) developed a document that uses lung function and clinical factors to determine if an individual patient with airways disease has features more consistent with asthma, COPD or the overlap. ${ }^{5}$ However, many of these factors are subjective and may be difficult to apply in epidemiologic studies or clinical trials.

We have previously reported on ACO within the COPD Genetic Epidemiology (COPDGene ${ }^{\circledR}$ ) study, a large observational study of smokers with and without COPD. ${ }^{6,7}$ We defined ACO based on smoking history of at least 10 pack years, airflow obstruction on spirometry (post-bronchodilator forced expiratory volume in 1 second [FEV 1 ] to forced vital capacity $[F V C]<0.7$ and $\mathrm{FEV}_{1}<80 \%$ predicted) and self-report of a physician diagnosis of asthma before the age of 40 . Compared to usual COPD, participants with ACO were younger and were more commonly female and African American. They have a greater number of COPD exacerbations and less emphysema and more airway disease on quantitative analysis of chest computed tomography (CT) scans.

Asthma, especially asthma with onset in childhood, has a strong atopic predisposition. The Dutch Hypothesis, put forward in 1961, proposes that there are common host factors for asthma and COPD, including airway hyperresponsiveness and atopy ${ }^{8}$; disease manifestations also depend on external factors, such as exposures. Cigarette smoking and atopy likely increase the risk for COPD development. ${ }^{9}$ COPD individuals with allergic sensitization have been shown to have increased respiratory symptoms and exacerbation rates, ${ }^{10}$ which is similar to our findings in ACO. ${ }^{6,7}$ The finding of a bronchial epithelial type 2 inflammatory gene expression signature in some COPD individuals suggests shared mechanisms with asthma. ${ }^{11}$ However, since bronchoscopy is not part of the standard evaluation in COPD or asthma, a bronchial epithelial gene expression is unlikely to be a clinically-applicable biomarker for ACO.

Therefore, we hypothesized that IgE could be used as a biomarker to refine our previous definition of ACO, which was based on clinical history and spirometry. To test that hypothesis, we measured total and specific IgE levels in a subset of the COPDGene ${ }^{\circledR}$ study, examining clinical and imaging features of participants with ACO and elevated IgE and/or allergic sensitization.

\section{Methods}

\section{Study Participants}

COPDGene ${ }^{\circledast}$ is an observational study conducted at 21 clinical centers across the United States. ${ }^{12}$ COPDGene ${ }^{\circledR}$ enrolled non-Hispanic white and African American individuals with a smoking history of at least 10 pack years. Individuals with previous lung resection and other significant lung diseases, except for asthma, were excluded. The baseline study visit included questionnaires on demographics, medical history, and disease-related quality of life, using the St George's Respiratory Questionnaire. ${ }^{13}$ Participants underwent spirometry before and after inhaled albuterol. Exercise capacity was measured by the 6-minute walk test. Inspiratory and expiratory chest CT scans with quantitative image analysis were used to assess emphysema (low attenuation areas at -950 Hounsfield units [HU]), gas trapping $(-856 \mathrm{HU}$ on expiratory scan), and airway wall thickening (wall area percentage of segmental airways). ${ }^{14}$ Blood was drawn for genetic analysis and measurement of biomarkers. In the longitudinal follow-up program, ${ }^{15}$ participants were asked to complete a telephone or web-based questionnaire every 6 months, assessing incident comorbidities and COPD exacerbations. Exacerbations were defined by the use of antibiotics and/or systemic steroids for a chest illness ${ }^{16}$; severe exacerbations led to an emergency department visit or hospitalization.

All participants provided written informed consent. The COPDGene ${ }^{\circledR}$ study was approved by the institutional review boards at all participating centers. 


\section{Immunoglobulin E Measurements}

We selected 2874 COPDGene $^{\circledR}$ participants in 4 groups defined by the presence or absence of $\mathrm{COPD}\left(\mathrm{FEV}_{1} / \mathrm{FVC}<0.7\right.$ and $\mathrm{FEV}_{1}<80 \%$ predicted, corresponding to GOLD spirometry grades 2-4) ${ }^{17}$ and self-reported asthma: asthma, COPD, ACO and controls. Control participants had normal spirometry $\left(\mathrm{FEV}_{1} / \mathrm{FVC} \geq 0.7\right.$ and $\mathrm{FEV}_{1} \geq 80 \%$ predicted) and no history of asthma. Plasma samples were sent to Phadia Immunology Reference Laboratory (Portage, Michigan) for measurements of total IgE levels and 6 specific IgE levels using Immunocap assays: cat dander, dog dander, dust mite (D. farinae and D. pteronyssinus), German cockroach and mold mix. For the specific IgE assays, we selected indoor aeroallergens based on a previous COPD study. ${ }^{10}$

To express total IgE as a quantitative outcome, values less than the lower limit of detection $(<2 \mathrm{IU} / \mathrm{ml})$ were set as half the lower limit $(1 \mathrm{IU} / \mathrm{ml})$ and values greater than assay (> $5000 \mathrm{IU} / \mathrm{ml}$ ) were set at the upper limit of detection (5000 IU/ml). We examined 2 thresholds for elevated total IgE levels. We used the common clinical cutoff of $100 \mathrm{IU} / \mathrm{ml}$ as well as a threshold of $30 \mathrm{IU} / \mathrm{ml}$ based on the prescribing information for omalizumab, ${ }^{18}$ a monoclonal antibody against IgE which is indicated for asthma treatment. For 5 of the specific IgE assays, we defined positive sensitization by a value $>0.35 \mathrm{IU} / \mathrm{ml}$. Mold mix was already reported by the lab as positive or negative. For subsequent analyses, atopy was defined by a total IgE level $>100$ $\mathrm{IU} / \mathrm{ml}$ or a positive specific IgE to at least 1 allergen.

\section{Statistical Analysis}

In participants with COPD, we defined broad ACO by a self-report of asthma and strict ACO by self-report of a doctor's diagnosis of asthma before the age of 40 , as per our previous studies. ${ }^{6,7}$ These groups were further subdivided by the presence of atopy, defined by IgE levels as above. Clinical and imaging features between groups were compared using t-tests or Chi-square tests, as appropriate. The frequency of exacerbations and the outcome of a severe exacerbation were analyzed using linear and logistic regression, respectively, adjusted for age, sex, race, smoking history, and $\mathrm{FEV}_{1} \%$ predicted. Analysis of wall area percentage of segmental airways used linear regression, adjusted for age, sex, race, current smoking, body mass index, and chest CT scanner model.

\section{Results}

\section{Study Participants and IgE Measurements}

Of the 2874 individuals selected, 4 individuals were excluded due to spirometry values that did not meet the definitions of COPD or control. Table 1 shows characteristics of study participants based on COPD and self-report of asthma. Compared to usual COPD, participants with the broad definition of ACO were younger and more commonly female and African American. Despite fewer pack years of smoking history, they had lower $\mathrm{FEV}_{1}$ and more exacerbations. On quantitative chest CT scan analysis, they had less emphysema and more airway wall thickening.

Participants with ACO had higher total IgE levels than usual COPD, as did participants with asthma alone compared to controls without airflow obstruction (Table 1). Over $2 / 3$ of ACO participants had total IgE > $30 \mathrm{IU} / \mathrm{ml}$ and nearly $40 \%$ had total $\mathrm{IgE}>100 \mathrm{IU} / \mathrm{ml}$. In ACO, the prevalence of sensitization to the 6 allergens ranged from $14 \%$ to $24 \%$, and over $40 \%$ of participants were sensitized to at least 1 allergen (Table 1, online supplement Table 1). These frequencies were higher than usual COPD, but slightly lower than asthma without COPD.

In each of the 4 subgroups based on COPD and asthma, we tested for concordance between having at least one positive specific IgE and an elevated total IgE, using 2 thresholds (online supplement Tables 2, 3). Overall, there was better concordance in the participants with asthma, with or without ACO, and there was better concordance using the higher total $\mathrm{IgE}$ cutoff of $100 \mathrm{IU} / \mathrm{ml}$. Based on these results, this threshold was used for subsequent analyses. Due to the potential effects of smoking on IgE levels, ${ }^{19}$ we examined the concordance between elevated total IgE and positive specific IgE stratified by current versus former smokers (online supplement Tables 4, 5). A higher proportion of current smokers had both elevated total IgE and at least one positive specific IgE.

\section{Asthma-COPD Overlap}

We then examined the various definitions of ACO. Table 1 shows the clinical and imaging characteristics of participants with the strict ACO definition, based on self-report of doctor's diagnosis of asthma before age 40 . The results are generally similar to those for the broad ACO definition based on any self-report of asthma and similar to those that we have previously 


\section{Table 1. Study Participants and Immunoglobulin E Results ${ }^{a}$}

\begin{tabular}{|c|c|c|c|c|c|}
\hline & $\begin{array}{c}\text { Control } \\
\text { (no COPD, } \\
\text { no asthma) }\end{array}$ & $\begin{array}{c}\text { Asthma } \\
\text { (asthma, } \\
\text { no COPD) }\end{array}$ & $\begin{array}{l}\text { Usual COPD } \\
\text { (COPD, } \\
\text { no asthma) }\end{array}$ & $\begin{array}{c}\text { Broad } \\
\text { Definition ACO } \\
\text { (COPD and } \\
\text { self-reported } \\
\text { asthma) }\end{array}$ & $\begin{array}{c}\text { Strict } \\
\text { Definition } \\
\text { ACO }^{\mathrm{b}}\end{array}$ \\
\hline $\mathbf{N}$ & 598 & 541 & 899 & $832^{\mathrm{e}}$ & 440 \\
\hline Age & $57.2(8.5)$ & $55.2(8.1)^{\mathrm{c}}$ & $63.9(8.5)$ & $61.9(8.6)^{d}$ & $60.4(8.7)^{\mathrm{d}}$ \\
\hline Male Gender & $321(53.7 \%)$ & $207(38.3 \%)^{\mathrm{c}}$ & $533(59.3 \%)$ & $371(44.6 \%)^{d}$ & $210(47.7 \%)^{\mathrm{d}}$ \\
\hline Race: Non-Hispanic White & $347(58.0 \%)$ & $264(48.8 \%)$ & $718(79.9 \%)$ & $554(66.6 \%)$ & $278(63.2 \%)$ \\
\hline African American & $251(42.0 \%)$ & $277(51.2 \%)^{\mathrm{c}}$ & $181(20.1 \%)$ & $278(33.4 \%)^{\mathrm{d}}$ & $162(36.8 \%)^{\mathrm{d}}$ \\
\hline Pack Years of Smoking & $37.4(20.0)$ & $36.5(20.5)$ & $54.7(29.3)$ & $48.5(26.2)^{\mathrm{d}}$ & $46.3(24.8)^{\mathrm{d}}$ \\
\hline Current Smoker & $364(60.9 \%)$ & $337(62.3 \%)$ & $383(42.6 \%)$ & $331(39.8 \%)$ & $191(43.4 \%)$ \\
\hline Body Mass Index, $\mathrm{kg} / \mathrm{m}^{2}$ & $29.0(5.7)$ & $30.0(6.6)^{\mathrm{c}}$ & $27.7(5.9)$ & $28.9(6.6)^{\mathrm{d}}$ & $29.1(6.9)^{\mathrm{d}}$ \\
\hline FEV $_{1} \%$ Predicted, Post-Bronchodilator & $98.2(11.7)$ & $95.9(10.8)^{\mathrm{c}}$ & $53.7(17.6)$ & $49.0(17.7)^{\mathrm{d}}$ & $50.3(17.9)^{\mathrm{d}}$ \\
\hline FEV $_{1} /$ FVC, Post-Bronchodilator & $0.79(0.05)$ & $0.78(0.05)^{\mathrm{c}}$ & $0.51(0.13)$ & $0.50(0.13)^{\mathrm{d}}$ & $0.51(0.13)$ \\
\hline Post-Bronchodilator Change in $\mathrm{FEV}_{1}, \mathrm{~L}$ & $0.09(0.16)$ & $0.11(0.17)^{\mathrm{c}}$ & $0.10(0.17)$ & $0.11(0.16)$ & $0.11(0.17)$ \\
\hline Number of Exacerbations in the Past Year & $0.1(0.4)$ & $0.4(0.9)^{\mathrm{c}}$ & $0.5(1.0)$ & $1.1(1.5)^{\mathrm{d}}$ & $1.2(1.5)^{\mathrm{d}}$ \\
\hline Severe Exacerbation in Past Year & $9(1.5 \%)$ & $74(13.7 \%)^{\mathrm{C}}$ & $145(16.1 \%)$ & $268(32.2 \%)^{\mathrm{d}}$ & $146(33.2 \%)^{\mathrm{d}}$ \\
\hline Chronic Bronchitis & $75(12.5 \%)$ & $109(20.2 \%)^{\mathrm{c}}$ & $219(24.4 \%)$ & $274(32.9 \%)^{\mathrm{d}}$ & $153(34.8 \%)^{\mathrm{d}}$ \\
\hline Hay Fever & $136(22.7 \%)$ & $271(50.1 \%)^{\mathrm{c}}$ & $204(22.7 \%)$ & $383(46.0 \%)^{\mathrm{d}}$ & $224(50.9 \%)^{d}$ \\
\hline \% Emphysema (-950HU) & $1.9(2.4)$ & $1.7(2.5)$ & $12.8(12.4)$ & $11.4(11.6)^{\mathrm{d}}$ & $9.5(10.6)^{d}$ \\
\hline \% Gas-trapping on Expiratory CT scan $(-856 \mathrm{HU})$ & $10.0(8.3)$ & $9.2(8.2)$ & $36.8(20.2)$ & $37.0(19.9)$ & $34.3(20.1)$ \\
\hline Wall Area $\%$ of Segmental Airways & $46.8(7.3)$ & $49.4(7.7)^{\mathrm{c}}$ & $54.6(7.7)$ & $56.5(7.8)^{\mathrm{d}}$ & $57.2(7.9)^{\mathrm{d}}$ \\
\hline Total IgE, $\log 10$ Transformed (SD) & $1.68(0.67)$ & $1.87(0.68)^{\mathrm{c}}$ & $1.65(0.73)$ & $1.84(0.72)^{\mathrm{d}}$ & $1.91(0.74)^{\mathrm{d}}$ \\
\hline Total IgE $>100 \mathrm{IU} / \mathrm{ml}$ & $186(31.1 \%)$ & $231(42.7 \%)^{\mathrm{c}}$ & $264(29.4 \%)$ & $330(39.7 \%)^{\mathrm{d}}$ & $205(46.6 \%)^{d}$ \\
\hline At Least 1 Positive Specific IgE & $181(30.3 \%)$ & $270(49.9 \%)^{\mathrm{c}}$ & $220(24.5 \%)$ & $362(43.5 \%)^{\mathrm{d}}$ & $243(55.2 \%)^{\mathrm{d}}$ \\
\hline
\end{tabular}

\footnotetext{
${ }^{\mathrm{a}}$ Mean (SD) or N (\%) are shown.

${ }^{\mathrm{b}}$ Strict asthma-COPD overlap is defined by $\mathrm{FEV}_{1} / \mathrm{FVC}<0.7, \mathrm{FEV}_{1}<80 \%$ predicted, and self-report of a doctor's diagnosis of asthma before age 40 .

${ }^{\mathrm{c}} P<0.05$ for comparison with no COPD, no asthma

${ }^{\mathrm{d}} P<0.05$ for comparison with COPD, no asthma

${ }^{\mathrm{e}}$ Two participants had failed total IgE assays
}

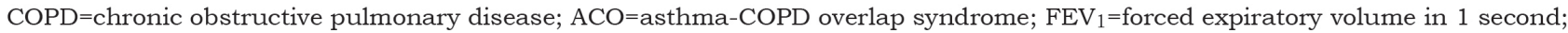
$\mathrm{FVC}=$ forced vital capacity; $\mathrm{HU}=$ Hounsfield unit; $\mathrm{CT}=$ computed tomography; IgE=immunoglobulin $\mathrm{E}$; $\mathrm{SD}=$ standard deviation

reported in the entire $\mathrm{COPDGene}^{\circledR}$ study. $^{7}$ Of the 831 participants with the broad definition of ACO, 450 were atopic based on total $\mathrm{IgE}>100 \mathrm{IU} / \mathrm{ml}$ and/or at least one positive specific IgE (Table 2). Compared to participants with COPD without asthma and without atopy, the participants with atopic ACO were younger and more commonly African American, though there was no longer a gender difference. These participants had lower FEV 1 and more exacerbations. They had a higher prevalence of chronic bronchitis symptoms, and more than half reported a history of hay fever. chest CT scans showed less emphysema and more airway thickening.

We then examined the 381 participants with ACO without atopy. Compared to atopic ACO (Table 2), these participants were more commonly women and non-Hispanic white. They had a greater lifetime smoking intensity but fewer were current smokers. They had lower $\mathrm{FEV}_{1}$, but exacerbation rates were not different. This group had a lower prevalence of hay fever compared to atopic ACO, but higher than COPD without asthma or atopy. Compared to atopic ACO, non-atopic ACO had more emphysema, but no difference in airway wall thickening. When participants with strict ACO definition were subcategorized by atopy, the results were generally similar to broad ACO with atopy (Table 3 ).

Figure 1 demonstrates the overlaps between the 


\section{Table 2. Participants with Broad ${ }^{a}$ Asthma-COPD Overlap and Atopy ${ }^{\mathrm{b}, \mathrm{c}}$}

\begin{tabular}{|c|c|c|c|c|c|}
\hline & $\begin{array}{l}\text { 1. Broad } \\
\text { ACO } \\
\text { with Atopy }\end{array}$ & $\begin{array}{l}\text { 2. COPD, } \\
\text { No Asthma, } \\
\text { No Atopy }\end{array}$ & $\begin{array}{c}P \text {-value for } \\
\text { Comparison } \\
\text { of Group } \\
1 \text { vs. } 2\end{array}$ & $\begin{array}{l}\text { 3. ACO } \\
\text { without } \\
\text { Atopy }\end{array}$ & $\begin{array}{c}P \text {-value for } \\
\text { Comparison } \\
\text { of Group } \\
1 \text { vs. } 3\end{array}$ \\
\hline $\mathbf{N}$ & 450 & 562 & & 381 & \\
\hline Age & $61.3(8.9)$ & 64.7 (8.3) & $<0.001$ & $62.4(8.2)$ & 0.06 \\
\hline Male Gender & $223(49.6 \%)$ & $299(53.2 \%)$ & 0.3 & $147(38.6 \%)$ & 0.002 \\
\hline Race: Non-Hispanic White & $265(58.9 \%)$ & $486(86.5 \%)$ & $<0.001$ & $288(75.6 \%)$ & $<0.001$ \\
\hline African American & $185(41.1 \%)$ & $76(13.5 \%)$ & & $93(24.4 \%)$ & \\
\hline Pack Years of Smoking & $46.5(26.2)$ & $55.5(28.0)$ & $<0.001$ & $50.9(26.1)$ & 0.02 \\
\hline Current Smoker & $195(43.3 \%)$ & $220(39.2 \%)$ & 0.2 & $136(35.7 \%)$ & 0.03 \\
\hline Body Mass Index, $\mathrm{kg} / \mathrm{m}^{2}$ & $28.9(6.7)$ & $27.5(5.9)$ & $<0.001$ & $28.9(6.5)$ & 1.0 \\
\hline FEV $_{1} \%$ Predicted, Post-Bronchodilator & $50.6(17.1)$ & $52.7(17.7)$ & 0.05 & $47.1(18.2)$ & 0.005 \\
\hline FEV 1 /FVC, Post-Bronchodilator & $0.51(0.12)$ & $0.50(0.13)$ & 0.5 & $0.48(0.13)$ & 0.005 \\
\hline Post-Bronchodilator Change in FEV $1, \mathrm{~L}$ & $0.11(0.18)$ & $0.10(0.15)$ & 0.1 & $0.10(0.15)$ & 0.4 \\
\hline Number of Exacerbations in the Past Year & $1.1(1.5)$ & $0.5(1.1)$ & $<0.001$ & $1.2(1.4)$ & 0.3 \\
\hline Severe Exacerbation in Past Year & $145(32.2 \%)$ & $89(15.8 \%)$ & $<0.001$ & $123(32.3 \%)$ & 1.0 \\
\hline Chronic Bronchitis & $148(32.9 \%)$ & $133(23.7 \%)$ & 0.001 & $126(33.1 \%)$ & 1.0 \\
\hline Hay Fever & $234(52 \%)$ & $108(19.2 \%)$ & $<0.001$ & $148(38.9 \%)$ & $<0.001$ \\
\hline \% Emphysema (-950HU) & $10.1(10.6)$ & $13.6(13.0)$ & $<0.001$ & $12.9(12.6)$ & 0.001 \\
\hline \% Gas-trapping on Expiratory CT scan $(-856 \mathrm{HU})$ & $35.3(19.9)$ & $38.0(20.3)$ & 0.06 & $38.9(19.9)$ & 0.02 \\
\hline Wall Area \% of Segmental Airways & $56.6(7.6)$ & $53.9(7.7)$ & $<0.001$ & $56.4(8.1)$ & 0.7 \\
\hline
\end{tabular}

${ }^{\mathrm{a}} \mathrm{Broad} \mathrm{ACO}$ is defined by $\mathrm{FEV}_{1} / \mathrm{FVC}<0.7, \mathrm{FEV}_{1}<80 \%$ predicted and self-report of asthma.

${ }^{\mathrm{b}}$ Atopy is defined by total $\mathrm{IgE}>100 \mathrm{IU} / \mathrm{ml}$ or at least one positive specific $\mathrm{IgE}$.

${ }^{\mathrm{C}}$ Mean (SD) or $\mathrm{N}(\%)$ is shown.

$\mathrm{COPD}=$ chronic obstructive pulmonary disease; $\mathrm{ACO}=$ asthma-COPD overlap syndrome; FEV $1=$ forced expiratory volume in 1 second; $\mathrm{FVC}=$ forced vital capacity; $\mathrm{HU}=$ Hounsfield unit; $\mathrm{CT}=\mathrm{computed}$ tomography; IgE=immunoglobulin $\mathrm{E}$; $\mathrm{SD}=$ standard deviation

participants with asthma, COPD, and atopy. There is high overlap between asthma and COPD (N=831 broad definition ACO), which was one of the selection criteria for this COPDGene ${ }^{\circledast}$ substudy. As above, a substantial number of participants with ACO did not have atopy $(\mathrm{N}=382)$. Conversely, there are many participants with atopic COPD, who also have the diagnosis of asthma $(\mathrm{N}=450)$. Figure 2 shows similar results, using the strict asthma definition.

\section{Comparison of ACO Definitions}

We tested 3 possible ACO definitions for association with exacerbations: COPD with strict asthma, COPD with asthma and atopy, and COPD with strict asthma and atopy. Each definition was similarly associated with number of exacerbations in the year prior to enrollment, using linear regression models (Table 4). The 3 definitions were similarly associated with the presence of a severe exacerbation in the prior year (online supplement Table 6), which is considered to be a marker of high risk in the GOLD guidelines. ${ }^{17}$ Only the first 2 definitions were significant predictors of exacerbations or severe exacerbations in the longitudinal follow-up (Table 4). All 3 definitions were similarly associated with airway wall thickening on chest CT scans (online supplement Table 7).

\section{Discussion}

In this study, we measured total and specific IgE levels in a large epidemiologic study of smokers with and without COPD, which included participants with a history of asthma. We used the presence of atopy to refine the definition of ACO, either based on COPD with any asthma history or our previous ACO definition based on self-report of a doctor's diagnosis of asthma before the age of 40. Similar to our previous results, ACO participants by any definition were younger, more commonly female or African American, and had similar levels of lung function impairment despite 


\section{Table 3. Participants with Strict ${ }^{\mathrm{a}}$ Asthma-COPD Overlap and Atopy ${ }^{\mathrm{b}, \mathrm{c}}$}

\begin{tabular}{|c|c|c|c|c|c|}
\hline & $\begin{array}{l}\text { 1. Strict } \\
\text { ACO } \\
\text { with Atopy }\end{array}$ & $\begin{array}{l}\text { 2. COPD, } \\
\text { No Asthma, } \\
\text { No Atopy }\end{array}$ & $\begin{array}{c}P \text {-value for } \\
\text { Comparison } \\
\text { of Group } \\
1 \text { vs. } 2\end{array}$ & $\begin{array}{l}\text { 3. Strict ACO } \\
\text { without } \\
\text { Atopy }\end{array}$ & $\begin{array}{c}P \text {-value for } \\
\text { Comparison } \\
\text { of Group } \\
1 \text { vs. } 3\end{array}$ \\
\hline $\mathbf{N}$ & 276 & 562 & & 164 & \\
\hline Age & $60.0(9.1)$ & $64.7(8.3)$ & $<0.001$ & $60.8(8.1)$ & 0.3 \\
\hline Male Gender & $151(54.7 \%)$ & 299 (53.2\%) & 0.7 & 59 (36.0\%) & $<0.001$ \\
\hline Race: Non-Hispanic White & $154(55.8 \%)$ & $486(86.5 \%)$ & $<0.001$ & $124(75.6 \%)$ & $<0.001$ \\
\hline African American & $122(44.2 \%)$ & $76(13.5 \%)$ & & $40(24.4 \%)$ & \\
\hline Pack Years of Smoking & $46.0(25.4)$ & $55.5(28.0)$ & $<0.001$ & $47.0(23.9)$ & 0.7 \\
\hline Current Smoker & $128(46.4 \%)$ & $220(39.2 \%)$ & 0.05 & $63(38.4 \%)$ & 0.1 \\
\hline Body Mass Index, $\mathrm{kg} / \mathrm{m}^{2}$ & $29.0(6.9)$ & $27.5(5.9)$ & 0.002 & $29.2(6.9)$ & 0.8 \\
\hline FEV 1 \% Predicted, Post-Bronchodilator & $51.7(17.0)$ & $52.7(17.7)$ & 0.4 & $48.1(19.0)$ & 0.05 \\
\hline FEV 1 /FVC, Post-Bronchodilator & $0.51(0.13)$ & $0.50(0.13)$ & 0.2 & $0.50(0.14)$ & 0.3 \\
\hline Post-Bronchodilator Change in FEV $1, \mathrm{~L}$ & $0.11(0.18)$ & $0.10(0.15)$ & 0.3 & $0.10(0.14)$ & 0.6 \\
\hline Number of Exacerbations in the Past Year & $1.0(1.5)$ & $0.5(1.1)$ & $<0.001$ & $1.4(1.5)$ & 0.03 \\
\hline Severe Exacerbation in Past Year & $88(31.9 \%)$ & $89(15.8 \%)$ & $<0.001$ & $58(35.4 \%)$ & 0.5 \\
\hline Chronic Bronchitis & $99(35.9 \%)$ & $133(23.7 \%)$ & $<0.001$ & $54(32.9 \%)$ & 0.6 \\
\hline Hay Fever & $156(56.5 \%)$ & $108(19.2 \%)$ & $<0.001$ & $68(41.5 \%)$ & 0.009 \\
\hline \% Emphysema (-950HU) & $8.8(9.9)$ & $13.6(13.0)$ & $<0.001$ & $10.7(11.8)$ & 0.1 \\
\hline \% Gas-trapping on Expiratory CT scan $(-856 \mathrm{HU})$ & $33.0(19.6)$ & $38.0(20.3)$ & 0.002 & $36.3(20.7)$ & 0.1 \\
\hline Wall Area \% of Segmental Airways & $57.2(7.9)$ & $53.9(7.7)$ & $<0.001$ & $57.2(8.0)$ & 0.9 \\
\hline
\end{tabular}

${ }^{\text {a }}$ Strict asthma-COPD overlap is defined by $\mathrm{FEV}_{1} / \mathrm{FVC}<0.7, \mathrm{FEV}_{1}<80 \%$ predicted and self-report of a doctor's diagnosis of asthma before age 40 .

${ }^{\mathrm{b}}$ Atopy is defined by total $\mathrm{IgE}>100 \mathrm{IU} / \mathrm{ml}$ or at least one positive specific IgE.

${ }^{\mathrm{c}}$ Mean (SD) or $\mathrm{N}(\%)$ is shown.

$\mathrm{COPD}=$ chronic obstructive pulmonary disease; $\mathrm{ACO}=$ asthma-COPD overlap syndrome; $\mathrm{FEV}$ =forced expiratory volume in 1 second; $\mathrm{FVC}=$ forced vital capacity; $\mathrm{HU}=$ Hounsfield unit; $\mathrm{CT}=$ computed tomography; $\mathrm{IgE}=$ immunoglobulin $\mathrm{E}$; $\mathrm{SD}=$ standard deviation

lower lifetime smoking intensity. ${ }^{6,7}$ ACO participants had more symptoms of hay fever and chronic bronchitis. Despite different participants meeting each of the ACO criteria, each definition was associated with COPD exacerbations (all exacerbations as well as severe exacerbations in the prior year) and airway wall thickening on chest CT scans. IgE levels did not clearly refine the clinical diagnosis of ACO. However, we did identify a subgroup of ACO without atopy, who were more likely to be non-Hispanic white women with higher lifetime smoking intensity but less current smoking, lower lung function, more emphysema but similar airway wall thickening and exacerbation rates.

Previous studies have examined IgE levels in ACO. Soler-Cataluna et al devised a definition of ACO, based on expert consensus, that included high $\operatorname{IgE}$ as a minor criterion, though no specific IgE threshold was provided. $^{20}$ This definition was applied to an observational study of 3125 COPD patients in
Spain. ${ }^{21}$ As expected, participants with ACO had higher IgE levels compared to other COPD patients. A Japanese study compared 37 ACO patients, defined based on GINA/GOLD criteria, ${ }^{5}$ to 220 usual COPD, finding ACO participants had a higher prevalence of elevated total IgE (>173 IU/ml, based on the reference range of the hospital laboratory) or a positive specific IgE to a panel of allergens largely similar to those in the present study. ${ }^{22}$ In a longitudinal study of 831 COPD patients in Spain, Cosio et al defined ACO by the GINA/GOLD criteria, augmented with major and minor criteria, the latter of which included total IgE $>100 \mathrm{IU} / \mathrm{ml} .{ }^{23}$ As expected, participants with ACO had higher IgE levels than no ACO. Almost all participants with ACO continued to meet criteria at 1-year followup and had better survival than non-ACO participants.

Even when using a strict definition of ACO based on clinical history and spirometry, we found participants with and without atopy. Asthma is recognized to be a 


\section{Figure 1. Venn Diagram Showing Overlaps Between Asthma, COPD and Atopy}

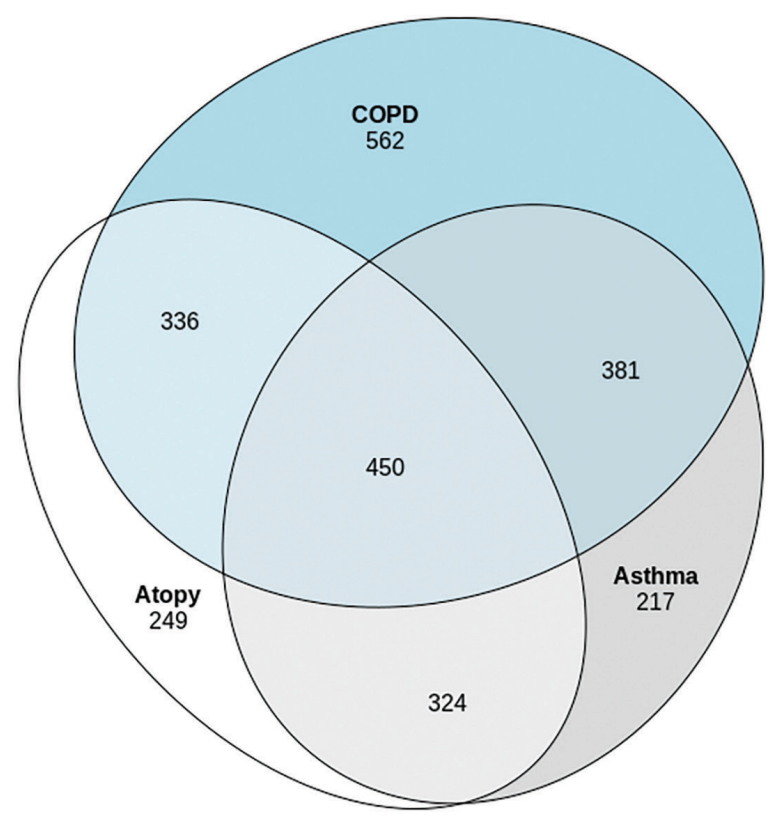

Atopy is defined by total $\mathrm{IgE}>100 \mathrm{IU} / \mathrm{ml}$ or at least one positive specific IgE.

$\mathrm{COPD}=$ chronic obstructive pulmonary disease; IgE=immunoglobulin $\mathrm{E}$

heterogeneous condition, and our study adds evidence to support that ACO is likely to be heterogeneous as well. ${ }^{1}$ In a study of 109 ACO patients, less than half were considered to have Th2-inflammation, based on blood or sputum eosinophilia. ${ }^{24}$ Barnes proposed subdividing ACO into eosinophilic, neutrophilic, and paucigranulocytic subtypes, based on sputum inflammatory cell patterns, and has suggested therapies for each subtype. ${ }^{25}$ Ghebre et al defined eosinophilic, neutrophilic, and mixed subgroups of asthma and COPD patients, based on sputum cytokines. $^{26}$ Interleukin (IL)-17 is one driver of neutrophilic inflammation in severe asthma and potentially COPD. ${ }^{27} \mathrm{COPD}$ participants with an IL17 bronchial gene expression pattern may be less responsive to inhaled corticosteroids. ${ }^{28}$

Agusti et al introduced the concept of treatable traits, which favors the use of treatable phenotypes over specific diagnostic categories of airway disease, such as COPD or asthma. ${ }^{29}$ Elevated total IgE is a treatable trait in asthma, which can be targeted

\section{Figure 2. Venn Diagram of Asthma, COPD and Atopy ${ }^{\mathrm{a}}$}

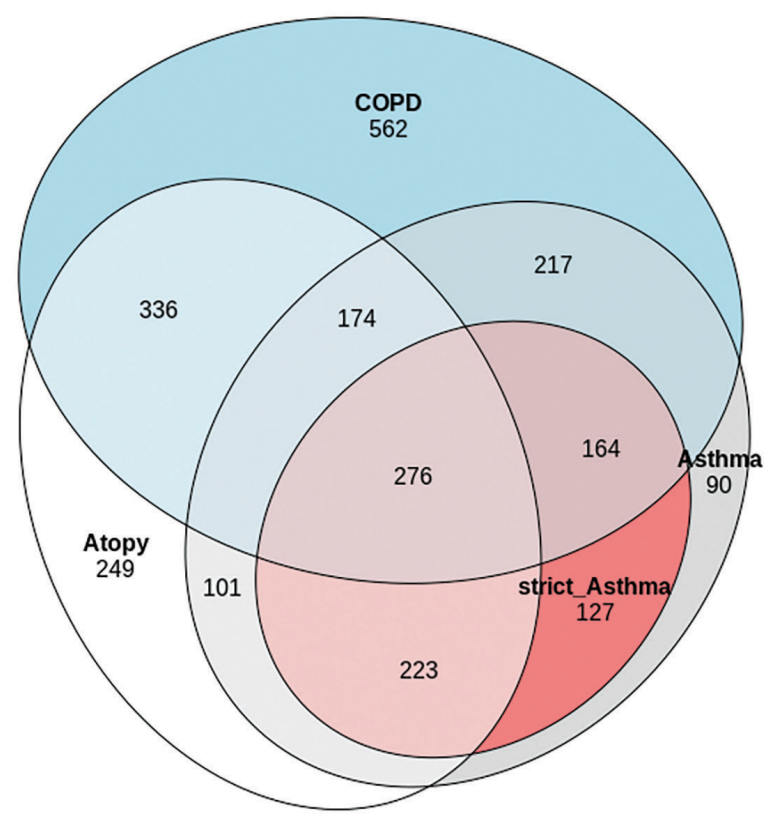

ancludes a strict definition of asthma, defined by self-report of a doctor's diagnosis of asthma before age 40 .

$\mathrm{COPD}=$ chronic obstructive pulmonary disease

with omalizumab, a monoclocal antibody to IgE. Omalizumab has been shown to be effective in the treatment of ACO in an Australian registry study ${ }^{30}$ and a post-hoc analysis of the PROSPERO clinical trial. ${ }^{31}$ Eosinophilia, frequently considered to be relevant in ACO, is another potential treatable trait in COPD, based on studies demonstrating effectiveness of mepolizumab, an anti-IL-5 antibody in COPD participants with elevated blood eosinophils. ${ }^{32} \mathrm{We}$ have previously shown that an eosinophil threshold $>300$ cells/ul had the strongest association with exacerbations in COPDGene ${ }^{\circledast}$, but had limited overlap with a clinical definition of ACO. ${ }^{33}$ However, the eosinophil counts were measured at the COPDGene ${ }^{\oplus}$ Phase 2 (5-year) visit, so we could not directly compare with the IgE levels in this study, which were measured at the baseline visit.

Besides the inability to directly correlate IgE levels with eosinophil counts, there are several limitations to our study. We relied on a self-report of asthma, which could be subject to recall bias or diagnostic misclassification. However, we have used this definition of ACO in previous studies in COPDGene ${ }^{\circledast}$, 


\section{Table 4. Linear Regression Models for Exacerbations Outcomes}

\begin{tabular}{|c|c|c|c|c|c|c|}
\hline & \multicolumn{2}{|c|}{$\begin{array}{l}\text { Strict ACO vs. COPD, } \\
\text { No Asthma }\end{array}$} & \multicolumn{2}{|c|}{$\begin{array}{c}\text { Broadb ACO with Atopy } \\
\text { Vs. COPD, No Asthma, } \\
\text { No Atopyc }\end{array}$} & \multicolumn{2}{|c|}{$\begin{array}{l}\text { Strict ACO with Atopy } \\
\text { vs. COPD, No Asthma, } \\
\text { No Atopyc }\end{array}$} \\
\hline & $\beta$ (SE) & $p$-value & $\beta$ (SE) & $p$-value & $\beta$ (SE) & $p$-value \\
\hline Exacerbations in Past Year & $0.56(0.07)$ & $<0.001$ & $0.52(0.08)$ & $<0.001$ & $0.52(0.09)$ & $<0.001$ \\
\hline $\begin{array}{l}\text { Exacerbations/ } \\
\text { Year in Longitudinal Follow-up }\end{array}$ & $0.23(0.06)$ & $<0.001$ & $0.17(0.07)$ & 0.017 & $0.11(0.08)$ & 0.17 \\
\hline $\begin{array}{l}\text { Severe Exacerbations/ } \\
\text { Year in Longitudinal Follow-up }\end{array}$ & $0.098(0.04)$ & 0.007 & $0.10(0.04)$ & 0.015 & $0.076(0.05)$ & 0.12 \\
\hline
\end{tabular}

${ }^{\text {a }}$ Strict asthma-COPD overlap is defined by $\mathrm{FEV}_{1} / \mathrm{FVC}<0.7, \mathrm{FEV}_{1}<80 \%$ predicted and self-report of a doctor's diagnosis of asthma before age 40.

${ }^{\mathrm{b}} \mathrm{Broad} \mathrm{ACO}$ is defined by defined by $\mathrm{FEV}_{1} / \mathrm{FVC}<0.7, \mathrm{FEV}_{1}<80 \%$ predicted, and self-report of asthma.

${ }^{\mathrm{c}}$ Atopy is defined by total $\mathrm{IgE}>100 \mathrm{IU} / \mathrm{ml}$ or at least one positive specific IgE.

All models are adjusted for age, sex, race, current smoking, pack years of smoking and $\mathrm{FEV}_{1} \%$ predicted.

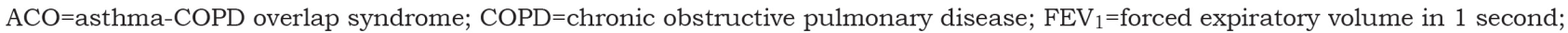
$\mathrm{FVC}=$ forced vital capacity; IgE=immunoglobulin $\mathrm{E}$

identifying both clinical and genetic associations. ${ }^{6,7}$ We assayed a limited number of specific IgE tests, based on a previous study in COPD. ${ }^{10}$ These allergens also showed some of the highest sensitization rates in the National Health and Nutrition Examination Survey, a sample of the U.S. population. ${ }^{34}$ Our study focused on indoor aeroallegens, since outdoor allergens may vary more by season and by region in the multi-center study, and since COPD patients usually spend more time indoors. ${ }^{35}$ Perhaps because of the limited panel of specific IgE tests, we found that elevated total IgE captured the majority of the atopic ACO participants (online supplement Table 3). In future studies, it would be relevant to examine a larger panel of specific IgE measurements, along with corresponding assessment of allergen exposures, which was not available in COPDGene ${ }^{\circledR}$.

By measuring total and specific IgE in a study of smokers with and without COPD, we identified participants with atopic asthma-COPD overlap, who were similar to participants with a clinical definition of ACO. Incorporating IgE did not improve prediction of exacerbation rates or airway wall thickening on chest CT scans compared to the strict clinical definition of ACO from our previous studies. Total and specific IgE measurements allowed us to subdivide ACO participants into those with and without atopy; the latter were more likely to be white men with greater lifetime smoking intensity, lower lung function and more emphysema on chest CT scans. It is likely that atopic ACO participants represent a subtype of COPD with a different mechanism of disease risk and progression, who would benefit from alternative therapeutic considerations. Further investigation using the wealth of molecular data in COPDGene ${ }^{\circledR}$ will be required to identify biologic mechanisms underlying non-atopic ACO. Currently, IgE levels are not a standard test in COPD management, nor are they included in consensus definitions for ACO. ${ }^{2,4,5}$ Routine measurement of $\mathrm{IgE}$ cannot be recommended currently based on the results of this study. However, peripheral eosinophilia is increasingly recognized as a treatable trait in COPD. ${ }^{29,36}$ Future studies will be required to determine the overlap between atopic ACO and eosinophilic COPD and whether IgE testing should be considered as part of the evaluation and management of a COPD patient.

\section{Acknowledgements}

COPDGene ${ }^{\circledR}$ Investigators - Core Units

Administrative Center: James D. Crapo, MD (PI); Edwin K. Silverman, MD, PhD (PI); Barry J. Make, MD; Elizabeth A. Regan, MD, PhD

Genetic Analysis Center: Terri Beaty, PhD; Ferdouse Begum, PhD; Peter J. Castaldi, MD, MSc; Michael Cho, MD; Dawn L. DeMeo, MD, MPH; Adel R. Boueiz, MD; Marilyn G. Foreman, MD, MS; Eitan HalperStromberg; Lystra P. Hayden, MD, MMSc; Craig P. Hersh, MD, MPH; Jacqueline Hetmanski, MS, MPH; 
Brian D. Hobbs, MD; John E. Hokanson, MPH, PhD; Nan Laird, PhD; Christoph Lange, PhD; Sharon M. Lutz, PhD; Merry-Lynn McDonald, PhD; Margaret M. Parker, PhD; Dandi Qiao, PhD; Elizabeth A. Regan, MD, $\mathrm{PhD}$; Edwin K. Silverman, MD, PhD; Emily S. Wan, MD; Sungho Won, Ph.D.; Phuwanat Sakornsakolpat, M.D.; Dmitry Prokopenko, Ph.D.

Imaging Center: Mustafa Al Qaisi, MD; Harvey O. Coxson, PhD; Teresa Gray; MeiLan K. Han, MD, MS; Eric A. Hoffman, PhD; Stephen Humphries, PhD; Francine L. Jacobson, MD, MPH; Philip F. Judy, PhD; Ella A. Kazerooni, MD; Alex Kluiber ; David A. Lynch, MB; John D. Newell, Jr., MD; Elizabeth A. Regan, MD, PhD; James C. Ross, PhD; Raul San Jose Estepar, PhD; Joyce Schroeder, MD; Jered Sieren; Douglas Stinson ; Berend C. Stoel, PhD; Juerg Tschirren, PhD; Edwin Van Beek, MD, PhD; Bram van Ginneken, PhD; Eva van Rikxoort, PhD; George Washko, MD; Carla G. Wilson, MS;

Pulmonary Function Testing Quality Assurance Center, Salt Lake City, Utah: Robert Jensen, PhD

Data Coordinating Center and Biostatistics, National Jewish Health, Denver, Colorado: Douglas Everett, PhD; Jim Crooks, PhD; Camille Moore, PhD; Matt Strand, PhD; Carla G. Wilson, MS

Epidemiology Core, University of Colorado Anschutz Medical Campus, Aurora, Colorado: John E. Hokanson, MPH, PhD; John Hughes, PhD; Gregory Kinney, MPH, PhD; Sharon M. Lutz, PhD; Katherine Pratte, MSPH; Kendra A. Young, PhD

Mortality Adjudication Core: Surya Bhatt, MD; Jessica Bon, MD; MeiLan K. Han, MD, MS; Barry Make, MD; Carlos Martinez, MD, MS; Susan Murray, ScD; Elizabeth Regan, MD; Xavier Soler, MD; Carla G. Wilson, MS

Biomarker Core: Russell P. Bowler, MD, PhD; Katerina Kechris, PhD; Farnoush Banaei-Kashani, Ph.D

\section{$\underline{\text { COPDGene }}{ }^{\circledR}$ Investigators - Clinical Centers}

Ann Arbor, Michigan: Jeffrey L. Curtis, MD; Carlos H. Martinez, MD, MPH; Perry G. Pernicano, MD

Baylor College of Medicine, Houston, Texas: Nicola Hanania, MD, MS; Philip Alapat, MD; Mustafa Atik,
MD; Venkata Bandi, MD; Aladin Boriek, PhD; Kalpatha Guntupalli, MD; Elizabeth Guy, MD; Arun Nachiappan, MD; Amit Parulekar, MD;

Brigham and Women's Hospital, Boston, Massachusetts: Dawn L. DeMeo, MD, MPH; Craig Hersh, MD, MPH; Francine L. Jacobson, MD, MPH; George Washko, MD

Columbia University, New York, New York: R. Graham Barr, MD, DrPH; John Austin, MD; Belinda D’Souza, MD; Gregory D.N. Pearson, MD; Anna Rozenshtein, MD, MPH, FACR; Byron Thomashow, MD

Duke University Medical Center, Durham, North Carolina: Neil MacIntyre, Jr., MD; H. Page McAdams, $\mathrm{MD}$; Lacey Washington, MD

HealthPartners Research Institute, Minneapolis, Minnesota: Charlene McEvoy, MD, MPH; Joseph Tashjian, MD

Johns Hopkins University, Baltimore, Maryland: Robert Wise, MD; Robert Brown, MD; Nadia N. Hansel, MD, $\mathrm{MPH}$; Karen Horton, MD; Allison Lambert, MD, MHS; Nirupama Putcha, MD, MHS

Los Angeles Biomedical Research Institute at Harbor UCLA Medical Center, Torrance, California: Richard Casaburi, PhD, MD; Alessandra Adami, PhD; Matthew Budoff, MD; Hans Fischer, MD; Janos Porszasz, MD, PhD; Harry Rossiter, PhD; William Stringer, MD

Michael E. DeBakey VAMC, Houston, Texas: Amir Sharafkhaneh, MD, PhD; Charlie Lan, DO

Minneapolis VA: Christine Wendt, MD; Brian Bell, MD

Morehouse School of Medicine, Atlanta, Georgia: Marilyn G. Foreman, MD, MS; Eugene Berkowitz, MD, $\mathrm{PhD}$; Gloria Westney, MD, MS

National Jewish Health, Denver, Colorado: Russell Bowler, MD, PhD; David A. Lynch, MB

Reliant Medical Group, Worcester, Massachusetts: Richard Rosiello, MD; David Pace, MD

Temple University, Philadelphia, Pennsylvania: Gerard Criner, MD; David Ciccolella, MD; Francis Cordova, 
MD; Chandra Dass, MD; Gilbert D’Alonzo, DO; Parag Desai, MD; Michael Jacobs, PharmD; Steven Kelsen, MD, PhD; Victor Kim, MD; A. James Mamary, MD; Nathaniel Marchetti, DO; Aditi Satti, MD; Kartik Shenoy, MD; Robert M. Steiner, MD; Alex Swift, MD; Irene Swift, MD; Maria Elena Vega-Sanchez, MD

University of Alabama, Birmingham, Alabama: Mark Dransfield, MD; William Bailey, MD; Surya Bhatt, MD; Anand Iyer, MD; Hrudaya Nath, MD; J. Michael Wells, $\mathrm{MD}$

University of California, San Diego, California: Joe Ramsdell, MD; Paul Friedman, MD; Xavier Soler, MD, PhD; Andrew Yen, MD

University of Iowa, Iowa City, Iowa: Alejandro P. Comellas, MD; Karin F. Hoth, PhD; John Newell, Jr., MD; Brad Thompson, MD

University of Michigan, Ann Arbor, Michigan: MeiLan K. Han, MD, MS; Ella Kazerooni, MD; Carlos H. Martinez, MD, MPH

University of Minnesota, Minneapolis, Minnesota: Joanne Billings, MD; Abbie Begnaud, MD; Tadashi Allen, MD
University of Pittsburgh, Pittsburgh, Pennsylvania: Frank Sciurba, MD; Jessica Bon, MD; Divay Chandra, MD, MSc; Carl Fuhrman, MD; Joel Weissfeld, MD, $\mathrm{MPH}$

University of Texas Health Science Center at San Antonio, San Antonio, Texas: Antonio Anzueto, MD; Sandra Adams, MD; Diego Maselli-Caceres, MD; Mario E. Ruiz, MD

\section{Author Contributions:}

$\mathrm{CPH}, \mathrm{LPH}, \mathrm{NP}$ were responsible for the study design and data collection. CPH, S. Zacharia, RPAC, AM, S. Zarei provided data analysis and all authors were responsible for manuscript writing and editing.

\section{Declaration of Interest}

Dr. Hersh reports grant support from the National Institutes of Health and Novartis for this study. He reports grant support from Boehringer-Ingelheim and personal fees from AstraZeneca and 23andMe outside of this study. None of the other authors report any disclosures related to this study. 


\section{References}

1. Maselli DJ, Hardin M, Christenson SA, et al. Clinical approach to the therapy of asthma-COPD overlap. Chest. 2019;155(1):168177. doi: https://doi.org/10.1016/j.chest.2018.07.028

2. Sin DD, Miravitlles M, Mannino DM, et al. What is asthmaCOPD overlap syndrome? Towards a consensus definition from a round table discussion. Eur Respir J. 2016;48(3):664-673. doi: https://doi.org/10.1183/13993003.00436-2016

3. O'Donnell DE, Aaron S, Bourbeau J, et al. Canadian Thoracic Society recommendations for management of chronic obstructive pulmonary disease - 2007 update. Can Respir J. 2007;14 (Suppl B):5B-32B. doi: https://doi.org/10.1155/2007/830570

4. Miravitlles M, Alvarez-Gutierrez FJ, Calle M, et al. Algorithm for identification of asthma-COPD overlap: consensus between the Spanish COPD and asthma guidelines. Eur Respir J. 2017;49(5). doi: https://doi.org/10.1183/13993003.00068-2017

5. Global Initiative for Asthma (GINA), Global initiative for chronic Obstructive Lung Disease (GOLD). Diagnosis of diseases of chronic airflow limitation: asthma, COPD and asthma-COPD overlap syndrome (ACOS). GINA website. https://ginasthma. org/wp-content/uploads/2019/11/GINA_GOLD_ACOS_2014wms.pdf. Published 2015. Accessed October 2019.

6. Hardin M, Silverman EK, Barr RG, et al. The clinical features of the overlap between COPD and asthma. Respir Res. 2011;12(1):127. doi: https://doi.org/10.1186/1465-9921-12-127

7. Hardin M, Cho M, McDonald ML, et al. The clinical and genetic features of COPD-asthma overlap syndrome. Eur Respir J. 2014;44(2):341-350.

doi: https://doi.org/10.1183/09031936.00216013

8. Sluiter HJ, Koeter GH, de Monchy JG, et al. The Dutch hypothesis (chronic non-specific lung disease) revisited. Eur Respir J. 1991;4(4):479-489.

9. Sherrill DL, Lebowitz MD, Halonen M, Barbee RA, Burrows B. Longitudinal evaluation of the association between pulmonary function and total serum IgE. Am J Respir Crit Care Med. 1995; 152(1):98-102.

doi: https://doi.org/10.1164/ajrccm.152.1.7599870

10. Jamieson DB, Matsui EC, Belli A, et al. Effects of allergic phenotype on respiratory symptoms and exacerbations in patients with chronic obstructive pulmonary disease. Am J Respir Crit Care Med. 2013;188(2):187-192.

doi: https://doi.org/10.1164/rccm.201211-2103OC

11. Christenson SA, Steiling K, van den Berge M, et al. AsthmaCOPD overlap. Clinical relevance of genomic signatures of type 2 inflammation in chronic obstructive pulmonary disease. Am J Respir Crit Care Med. 2015;191(7):758-766. doi: https://doi.org/10.1164/rccm.201408-14580C
12. Regan EA, Hokanson JE, Murphy JR, et al. Genetic epidemiology of COPD (COPDGene) study design. COPD. 2010;7(1):32-43. doi: https://doi.org/10.3109/15412550903499522

13. Jones PW, Quirk FH, Baveystock CM, Littlejohns P. A selfcomplete measure of health status for chronic airflow limitation. The St George's Respiratory Questionnaire. Am Rev Respir Dis. 1992;145(6):1321-1327.

doi: https://doi.org/10.1164/ajrccm/145.6.1321

14. Bhatt SP, Washko GR, Hoffman EA, et al. Imaging advances in chronic obstructive pulmonary disease. insights from the genetic epidemiology of chronic obstructive pulmonary disease (COPDGene) study. Am J Respir Crit Care Med. 2019;199(3):286301. doi: https://doi.org/10.1164/rccm.201807-1351SO

15. Stewart JI, Moyle S, Criner GJ, et al. Automated telecommunication to obtain longitudinal follow-up in a multicenter cross-sectional COPD study. COPD. 2012;9(5):466472. doi: https://doi.org/10.3109/15412555.2012.690010

16. Busch R, Han MK, Bowler RP, et al. Risk factors for COPD exacerbations in inhaled medication users: the COPDGene study biannual longitudinal follow-up prospective cohort. BMC Pulm Med. 2016;16(1):28.

doi: https://doi.org/10.1186/s12890-016-0191-7

17. Global Initiative for Chronic Obstructive Lung Disease (GOLD). Global strategy for the diagnosis, management and prevention of COPD: 2019 Report. GOLD website. https://goldcopd.org/ gold-reports/ . Published 2019. Accessed October 2019.

18. Genetech. Xolair prescribing information. Genetech website. http://www.gene.com/download/pdf/xolair_prescribing.pdf. Published 2014. Accessed October 2019.

19. Omenaas E, Bakke P, Elsayed S, Hanoa R, Gulsvik A. Total and specific serum IgE levels in adults: relationship to sex, age and environmental factors. Clin Exp Allergy.1994;24(6):530-539. doi: https://doi.org/10.1111/j.1365-2222.1994.tb00950.x

20. Soler-Cataluna JJ, Cosio B, Izquierdo JL, et al. Consensus document on the overlap phenotype COPD-asthma in COPD. Arch Bronconeumol. 2012;48(9):331-337.

doi: https://doi.org/10.1016/j.arbres.2011.12.009

21. Barrecheguren M, Roman-Rodriguez M, Miravitlles M. Is a previous diagnosis of asthma a reliable criterion for asthmaCOPD overlap syndrome in a patient with COPD? Int J Chron Obstruct Pulmon Dis. 2015;10(1):1745-1752. doi: https://doi.org/10.2147/COPD.S87025

22. Kobayashi S, Hanagama M, Yamanda S, Ishida M, Yanai M. Inflammatory biomarkers in asthma-COPD overlap syndrome. Int J Chron Obstruct Pulmon Dis. 2016;11(1):2117-2123. doi: https://doi.org/10.2147/COPD.S113647

23. Cosio BG, Soriano JB, Lopez-Campos JL, et al. Defining the asthma-COPD overlap syndrome in a COPD cohort. Chest. 2016;149(1):45-52. doi: https://doi.org/10.1378/chest.15-1055 
24. Cosio BG, Perez de Llano L, Lopez Vina A, et al. Th-2 signature in chronic airway diseases: towards the extinction of asthmaCOPD overlap syndrome? Eur Respir J. 2017;49(5). doi: https://doi.org/10.1183/13993003.02397-2016

25. Barnes PJ. Therapeutic approaches to asthma-chronic obstructive pulmonary disease overlap syndromes. J Allergy Clin Immunol. 2015;136(3):531-545.

doi: https://doi.org/10.1016/j.jaci.2015.05.052

26. Ghebre MA, Bafadhel M, Desai D, et al. Biological clustering supports both "Dutch" and "British" hypotheses of asthma and chronic obstructive pulmonary disease. J Allergy Clin Immunol. 2015;135(1):63-72. doi: https://doi.org/10.1016/j.jaci.2014.06.035

27. Roos AB, Stampfli MR. Targeting Interleukin-17 signalling in cigarette smoke-induced lung disease: mechanistic concepts and therapeutic opportunities. Pharmacol Ther. 2017; 178:123131. doi: https://doi.org/10.1016/j.pharmthera.2017.04.001

28. Christenson SA, van den Berge M, Faiz A, et al. An airway epithelial IL-17A response signature identifies a steroidunresponsive COPD patient subgroup. $J$ Clin Invest. 2018;129(1):169-181. doi: https://doi.org/10.1172/JCI121087

29. Agusti A, Bel E, Thomas M, et al. Treatable traits: toward precision medicine of chronic airway diseases. Eur Respir J. 2016;47(2):410419. doi: https://doi.org/10.1183/13993003.01359-2015

30. Maltby S, Gibson PG, Powell H, McDonald VM. Omalizumab treatment response in a population with severe allergic asthma and overlapping COPD. Chest. 2017;151(1):78-89.

doi: https://doi.org/10.1016/j.chest.2016.09.035

31. Hanania NA, Chipps BE, Griffin NM, et al. Omalizumab effectiveness in asthma-COPD overlap: post hoc analysis of PROSPERO. J Allergy Clin Immunol. 2019;143(4):1629-1633. doi: https://doi.org/10.1016/j.jaci.2018.11.032

32. Pavord ID, Chanez P, Criner GJ, et al. Mepolizumab for eosinophilic chronic obstructive pulmonary disease. $N$ Engl $J$ Med. 2017;377(17):1613-1629.

doi: https://doi.org/10.1056/NEJMoa 1708208

33. Yun JH, Lamb A, Chase R, et al. Blood eosinophil count thresholds and exacerbations in patients with chronic obstructive pulmonary disease. J Allergy Clin Immunol. 2018;141(6): 20372047. doi: https://doi.org/10.1016/j.jaci.2018.04.010

34. Salo PM, Arbes SJ Jr, Jaramillo R, et al. Prevalence of allergic sensitization in the United States: results from the National Health and Nutrition Examination Survey (NHANES) 20052006. J Allergy Clin Immunol. 2014;134(2):350-359.

doi: https://doi.org/10.1016/j.jaci.2013.12.1071

35. Donaldson GC, Wilkinson TM, Hurst JR, Perera WR, Wedzicha JA. Exacerbations and time spent outdoors in chronic obstructive pulmonary disease. Am J Respir Crit Care Med. 2005;171(5):446452. doi: https://doi.org/10.1164/rccm.200408-1054OC
36. Riley CM, Sciurba FC. Diagnosis and outpatient management of chronic obstructive pulmonary disease: a review. JAMA. 2019;321(8):786-797. doi: https://doi.org/10.1001/jama.2019.0131 